\title{
Ordered Nanocrystalline ZnO Films For High Speed and Transparent Thin Film Transistors
}

\author{
Burhan Bayraktaroglu and Kevin Leedy \\ Air Force Research Laboratory, Sensors Directorate, AFRL/RYDD \\ Wright Patterson AFB, OH 45433, USA \\ Email: burhan.bayraktaroglu@us.af.mil
}

\begin{abstract}
Thin films of spontaneously ordered and closely packed $20-50 \mathrm{~nm}$ diameter nanocolumns of $\mathrm{ZnO}$ were used to fabricate high speed and transparent thin film transistors (TFT). The use of nanocrystalline $\mathrm{ZnO}$ (nc-ZnO) helps to achieve the intrinsic electronic properties of single crystals while providing substrate agnostic thin films that can be grown on non-planar surfaces of rigid or flexible substrates. We have developed low temperature pulsed laser deposition (PLD) techniques for both doped and undoped nc-ZnO films and demonstrated microwave transistor operation $\left(f_{\max }=10 \mathrm{GHz}\right)$. Unlike in amorphous TFTs, the operation of nc$\mathrm{ZnO}$ transistors relies on field effect charge control at vertical grain boundaries between nanocolumns and can produce very high on/off ratios $\left(>10^{12}\right)$, very high current densities and near ideal subthreshold voltage swings $(\sim 85 \mathrm{mV} /$ decade). Using a combination of doped and undoped nc- $\mathrm{ZnO}$ films, we have fabricated the first indium-free transparent TFTs with excellent performance and transparency.
\end{abstract}

Index Terms - Nanocrystalline, nanocolumns, ZnO, TFT, TTFT, PLD.

\section{INTRODUCTION}

Thin film transistors made from amorphous or organic semiconductors are commonly used in the control circuits of large area display electronics such as flat panel TV screens. They can also be used in applications requiring flexible or non-planar surfaces where the use of regular single crystal electronics is problematic. The usefulness of TFTs, however, has not been extended to high performance applications due to the orders of magnitude lower electronic properties of thin films compared to their single crystal counterparts. For example, the electron mobility of amorphous $\mathrm{Si}$ is typically less than $1 \mathrm{~cm}^{2} / \mathrm{V} . \mathrm{s}$ and the severe threshold problems of poly-Si TFTs limit their usefulness [1 ]. Metal-oxide semiconductors based on $\mathrm{Zn}$, In, Ga, and Hf have shown great promise in solving these problems for current and next generation flat panel display electronics [2]. However, most metal-oxide semiconductor thin films are also amorphous and have limitations in current density and switching on/off ratios. Although they offer higher electron mobilities than amorphous Si films and therefore show promise in higher data rate circuit applications, they are still not sufficient for high performance digital or analog circuits.

Ordered nc- $\mathrm{ZnO}$ thin films composed of closely packed 20-50nm diameter nanocolumns offer a unique solution to improving TFT performance to levels comparable to single crystal semiconductors while maintaining their thin film properties. Because $\mathrm{ZnO}$ is a wide bandgap semiconductor, it can be used both as a transparent semiconductor and conductor for transparent electronics applications. We have shown that all-ZnO transparent transistors can be fabricated using nc-ZnO films with state-of-the art performance.

\section{THIN FILM DEPOSITION AND DEVICE FABRICATION}

Nc-ZnO films were deposited in a Neocera Pioneer 180 pulsed laser deposition system with a $\mathrm{KrF}$ excimer laser (Lambda Physik COMPex Pro 110, $\lambda=248$ nm, 10ns pulse duration). The following processing conditions were used to deposit undoped $\mathrm{ZnO}$ films for active layers of transistors: laser energy density of $2.6 \mathrm{~J} / \mathrm{cm}^{2}$, laser repetition rate of 30 $\mathrm{Hz}$, deposition temperature of $25^{\circ} \mathrm{C}$ to $200^{\circ} \mathrm{C}$, oxygen partial pressure of 1-100mTorr during the deposition, and substrateto-target distance of $9.5 \mathrm{~cm}$. The target was a $50 \mathrm{~mm}$ diameter by $6 \mathrm{~mm}$ thick sintered $\mathrm{ZnO}$ ceramic disk (99.999\%) [3]. The deposition parameters for conductive transparent $\mathrm{ZnO}$ films (used as contact layers in transparent transistors) were the same except that Ar gas was used during deposition instead of oxygen [4] and the source material was high purity $\mathrm{ZnO}$ with $3 \% \mathrm{Ga}_{2} \mathrm{O}_{3}$ used as an ntype dopant. Various gate insulators including $\mathrm{SiO}_{2}, \mathrm{Al}_{2} \mathrm{O}_{3}$ and $\mathrm{HfO}_{2}$ were used in this study. $\mathrm{SiO}_{2}$ films were grown in a PlasmaTherm 790 Plasma Enhanced Chemical Vapor Deposition (PECVD) system at $250^{\circ} \mathrm{C} . \mathrm{Al}_{2} \mathrm{O}_{3}$ and $\mathrm{HfO}_{2}$ films were prepared in a Cambridge Nanotech Fiji F200 Atomic Layer Deposition (ALD) system at $150-250^{\circ} \mathrm{C}$.

The $\mathrm{ZnO}$ crystal structure was determined by using a PANalytical X'Pert Pro MRD x-ray diffractometer. Film morphologies were analyzed with an FEI DB235 scanning electron microscope (SEM) and a JEOL 4000EX transmission electron microscope (TEM) operating at 400 $\mathrm{kV}$. Surface roughness was measured with a Veeco Dimension 3000 atomic force microscope (AFM). Dielectric film thickness and refractive index were measured with a Horiba Jobin Yvon UVISEL spectroscopic ellipsometer. Optical transmission measurements were made with a Varian Cary 5000 spectrophotometer.

Devices for low frequency characterization were fabricated on $\mathrm{Si}$ wafers, quartz or flexible polyimide films. The gate lengths, $\mathrm{L}_{\mathrm{G}}$, were varied from 2 to $25 \mu \mathrm{m}$. Higher resistivity substrates $(>2000 \mathrm{ohm} . \mathrm{cm})$ were used for high speed device fabrication to minimize capacitive parasitics. Gate lengths for these devices varied from $1.2 \mu \mathrm{m}$ to $3 \mu \mathrm{m}$. A 
bottom-gate configuration was used for both non-transparent and transparent transistors. $\mathrm{Ni} / \mathrm{Au}$ and $\mathrm{Ti} / \mathrm{Au}$ contacts were used as the gate and the source/drain contacts for the nontransparent devices, whereas Ga-doped $\mathrm{ZnO}$ (GZO) films were used as contacts for the transparent devices. Other device processing details were reported elsewhere [3]. As indicated in the cross sectional schematic of a multi-finger device in Figure 1, nc- $\mathrm{ZnO}$ film is produced conformably over the gate insulator. The source and drain contacts overlap the gate contact by $0.5-3 \mu \mathrm{m}$. The gate length is defined as the distance between the source and drain contacts. No intentional surface passivation was applied to the free surface of the $\mathrm{ZnO}$ film.

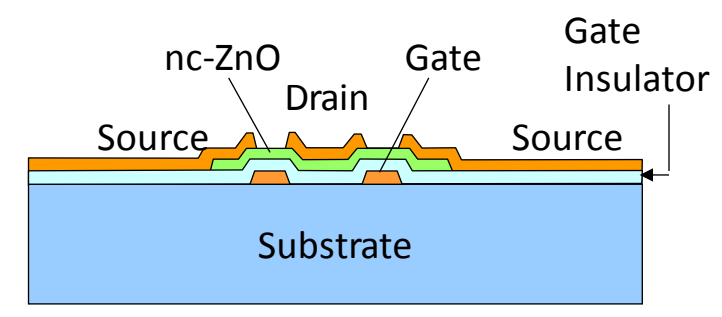

Figure 1: Cross-sectional schematic of nc- $\mathrm{ZnO}$ thin film transistor.

\section{THIN FILM ANALYSIS}

Cross sectional TEM images of $\mathrm{ZnO}$ films deposited conformably over the gate contact indicate that the film is composed of densely compacted, highly faulted columnarshaped grains that predominantly extend through the thickness of the film, as shown in Figure 2. At deposition temperatures of $<75^{\circ} \mathrm{C}$, grains exhibited diffraction contrast differences and, in some areas, nearly equiaxed grain structures. As film growth temperature elevated from $100^{\circ} \mathrm{C}$ to $400^{\circ} \mathrm{C}$, films displayed an increasingly uniform columnar grain structure and consistent diffraction contrast.The nanocolumnar grain diameters were in the $20-50 \mathrm{~nm}$ range depending on the film growth parameters such as substrate temperature and oxygen pressure, but self-ordering of nanocolums was observed with films grown on other types of gate insulators also, as shown in Figure 3.

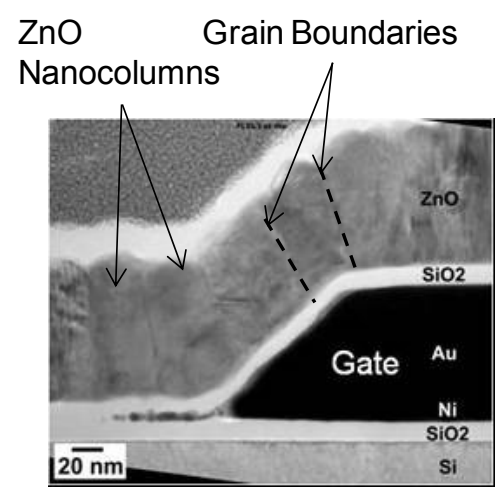

Figure 2: Cross sectional TEM image of $\mathrm{ZnO}$ film over the gate metal showing continuous closely-packed nanocolumnar structures over nonplanar surfaces. Arrows indicate the location of some of the nanocolumns and the vertical grain boundaries.
$\mathrm{X}$-ray diffraction scans of the $\mathrm{ZnO}$ films deposited on $\mathrm{SiO}_{2}, \mathrm{Al}_{2} \mathrm{O}_{3}$ and $\mathrm{HfO}_{2}$ gate dielectrics exhibited a highly textured c-axis orientation with only the $\mathrm{ZnO}$ (002) peak present, consistent with other studies of PLD $\mathrm{ZnO}$ films $[5,6,7,8]$. With increasing deposition temperature up to $400^{\circ} \mathrm{C}$, the intensities of the $\mathrm{ZnO}(002)$ peak increased and full-width at half-maximum values of the $\mathrm{ZnO}$ (002) decreased, indicating improved film crystallinity. $2 \Theta$ positions were less than the $34.421^{\circ} 2 \Theta(002)$ peak from the JCPDS \#36-1451 powder diffraction file indicating strained lattice structures. Progressively higher $\mathrm{ZnO}$ (002) peak intensities were obtained from $\mathrm{ZnO}$ films deposited on $\mathrm{HfO}_{2}$, $\mathrm{SiO}_{2}$, and $\mathrm{Al}_{2} \mathrm{O}_{3}$, respectively. As shown in Figure 3, larger $\mathrm{ZnO}$ grains with a rougher surface texture were found on films grown on $\mathrm{HfO}_{2}$, consistent with the diminished x-ray diffraction intensity observed. Further details on XRD results are given elsewhere [9].
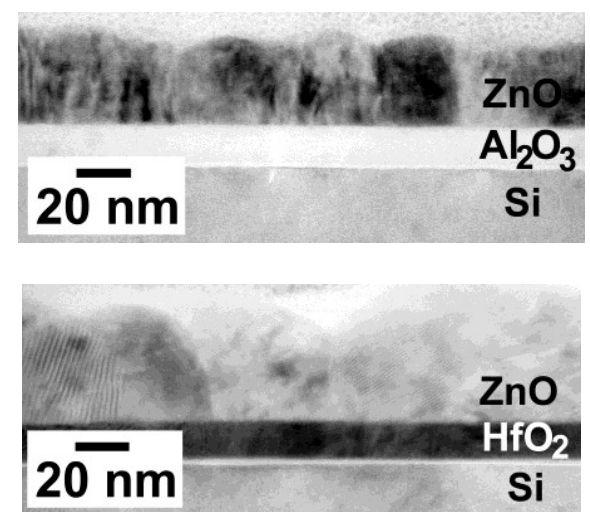

Figure 3: Cross sectional TEM images of $\mathrm{ZnO}$ thin film deposited at $200^{\circ} \mathrm{C}$ on $20 \mathrm{~nm} \mathrm{Al}{ }_{2} \mathrm{O}_{3} / \mathrm{Si}$. and $\mathrm{H}_{\mathrm{f}} \mathrm{O}_{2} / \mathrm{Si}$.

The RMS surface roughness of $\mathrm{ZnO}$ films deposited on $\mathrm{SiO}_{2}$ and $\mathrm{HfO}_{2}$ was $0.65 \mathrm{~nm}$ and $0.94 \mathrm{~nm}$, respectively, as measured by AFM. AFM images in Figure 4 also show slightly larger $\mathrm{ZnO}$ grains grown on $\mathrm{HfO}_{2}$ compared to $\mathrm{SiO}_{2}$ in agreement with cross sectional TEM results. The measured surface roughness of the underlying dielectric material was approximately $0.2 \mathrm{~nm}$ regardless of film composition, deposition technique or deposition temperature. This smooth surface was necessary for ordered $\mathrm{ZnO}$ grain growth and produced a well defined dielectric$\mathrm{ZnO}$ interface, which was essential for device performance.

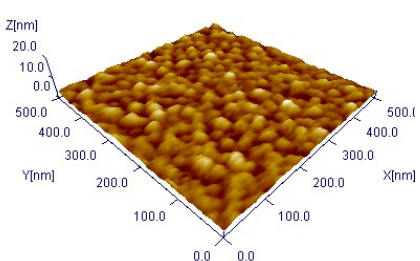

(a)

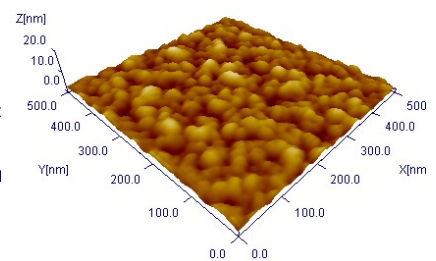

(b)
Figure 4: AFM images of $\mathrm{ZnO}$ thin films deposited at $200^{\circ} \mathrm{C}$ on a) $20 \mathrm{~nm}$ $\mathrm{SiO}_{2} / \mathrm{Si}$ and $\mathrm{HfO}_{2} / \mathrm{Si}$. 


\section{THIN FILM TRANSISTORS}

\section{A. DC Characteristics}

Typical common-source $\mathrm{I}-\mathrm{V}$ characteristics of nc- $\mathrm{ZnO}$ TFTs fabricated on various gate insulators is shown in Figure 5. The $\mathrm{ZnO}$ film was grown at $200^{\circ} \mathrm{C}$ in identical growth conditions and devices were fabricated in the same fabrication batch for direct comparison of results. All devices showed hysteresis-free operation and positive threshold voltages of $1.5 \pm 0.6 \mathrm{~V}$. As expected, higher dielectric constants of $\mathrm{Al}_{2} \mathrm{O}_{3}$ and $\mathrm{HfO}_{2}$ result in higher drain currents for the same gate voltage (i.e. higher transconductance) and flatter current characteristics in the saturation region. The influence of gate insulator on the device transconductance is shown in Figure 6. The same reciprocal dependence of transconductance on gate length was obtained for these insulators in the gate length range of $\mathrm{L}_{\mathrm{G}}=2-25 \mu \mathrm{m}$. This indicates that device scaling is not influenced by the surface states at the insulator- $\mathrm{ZnO}$ interface or at the back surface of the $\mathrm{ZnO}$ film.

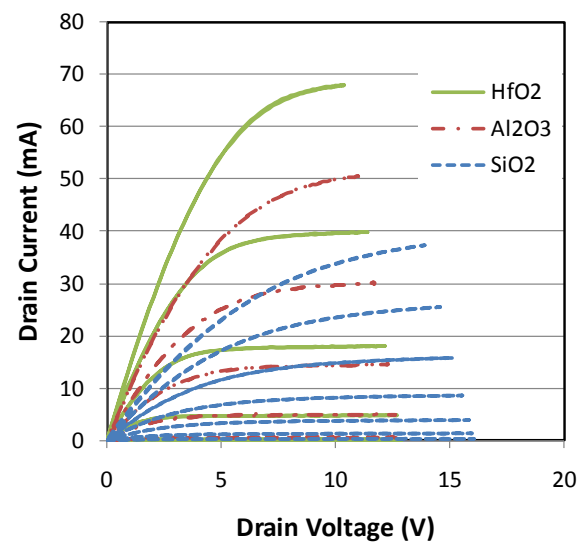

Figure 5: I-V characteristics of nc-ZnO TFTs with various gate insulators Gate insulator thickness $=30 \mathrm{~nm}, \mathrm{~L}_{\mathrm{G}}=5 \mu \mathrm{m}, \mathrm{W}_{\mathrm{G}}=400 \mu \mathrm{m}, \mathrm{V}_{\mathrm{G}}=2 \mathrm{~V} / \mathrm{step}$.

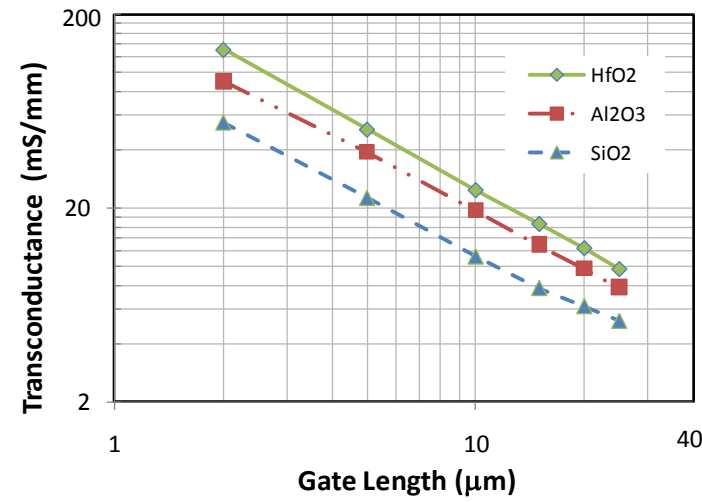

Figure 6: Transconductance dependence on gate length for 3 different gate insulators. $\mathrm{V}_{\mathrm{D}}=12 \mathrm{~V}, \mathrm{~V}_{\mathrm{G}}=10 \mathrm{~V}$.

Low surface state density values can also be inferred from the sub-threshold voltage swing, S, values. Transfer characteristics of a device fabricated on polyimide substrates using low temperature processing $\left(<150^{\circ} \mathrm{C}\right)$ and with a high$\kappa$ dielectric $\mathrm{HfO}_{2}$ insulator is shown in Figure 7 for various drain bias conditions. The measured S-value of $85 \mathrm{mV} /$ decade corresponds to a total surface state density of $1.96 \times 10^{12} \mathrm{~cm}^{-2}$ using the expression developed in [10]. The transfer characteristics also show very high on/off ratios of about $10^{12}$, which is typical for nc-ZnO TFTs fabricated on other substrates [11]. The maximum field effect mobility for the low temperature nc-ZnO TFT was $63 \mathrm{~cm}^{2} / \mathrm{V}$.s, as shown in Figure 8.

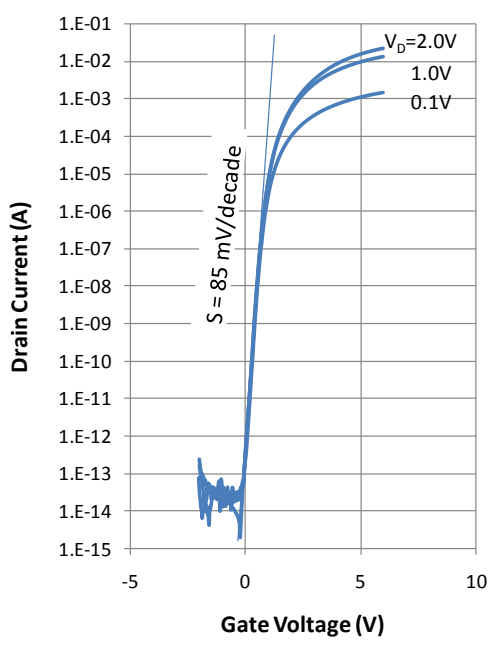

Figure 7: Transfer characteristics nc-ZnO TFT on polyimide substrate. The maximum process temperature was $150^{\circ} \mathrm{C}$.

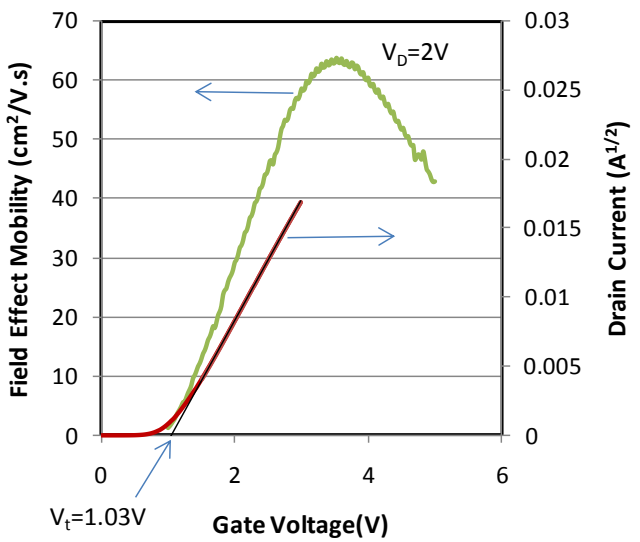

Figure 8: Field effect electron mobility and drain current as a function of gate voltage for $\mathrm{nc}-\mathrm{ZnO}$ TFT fabricated on polyimide substrate at low temperatures. $\mathrm{L}_{\mathrm{G}}=5 \mu \mathrm{m}, \mathrm{W}_{\mathrm{G}}=400 \mu \mathrm{m}$.

We interpret these record performance values for nc$\mathrm{ZnO}$ TFTs deposited in $\mathrm{O}_{2}$ to be a result of high crystal quality preserved within nanocolumns as well as the presence of acceptor-like charges at the grain boundaries due to Zn-vacancies [12]. Transistors show exceptionally low leakage currents in the OFF state due to back-to-back depletion layers formed at the vertical grain boundaries, which effectively block horizontal current conduction between the source and the drain contacts.

In the ON state, the vertical depletion layers collapse under the influence of gate field and large current densities are made possible between nanocrystals. This is similar to 
high current conduction in microcrystalline $\mathrm{ZnO}$-based varistors where back-to-back depletion layers at grain boundaries rapidly collapse at high electric fields [13]. A combination of low leakage current in the OFF state and large current density in the $\mathrm{ON}$ state produces the observed very high ON/OFF ratios.

Other contributing factors to large current density operation are the high electron mobility and low interface state density described above. Record field effect electron mobility values $\left(110 \mathrm{~cm}^{2} / \mathrm{V} . \mathrm{s}\right)[11]$ and low surface state densities $\left(2.51 \times 10^{11} \mathrm{~cm}^{-2}\right)$ [3] were obtained with nc-ZnO devices fabricated on $\mathrm{SiO}_{2}$ gate insulators. Such low interface state densities are consistent with the measured high field effect mobility.

\section{B. High Speed Transistors}

Thin film transistors are mostly used in circuits that do not require high speed operation [1] because of electron mobility limitations. However, with the demonstrated high electron mobility and the anticipated high electron velocity [14], nc-ZnO TFTs were shown to be suitable for smallsignal amplification at microwave frequencies [11,15].

Various device designs with varying degrees of overlap between source/drain contacts and the gate contact were examined to optimize the high frequency performance for devices with $\mathrm{L}_{\mathrm{G}}=1.2 \mu \mathrm{m}$ and $\mathrm{W}_{\mathrm{G}}=2 \times 50 \mu \mathrm{m}$. The calculated maximum available gain (MAG) and current gain $\left(\left|\mathrm{h}_{21}\right|^{2}\right)$ values from the measured s-parameters are shown in Figure 9. All three device designs (with 1.5, 1.0 and $0.5 \mu \mathrm{m}$ of gate electrode overlap with source/drain contacts) showed an identical current gain cut off frequency of $2.9 \mathrm{GHz}$. The highest power cut-off frequency was $\mathrm{f}_{\max }=10 \mathrm{GHz}$ for devices with $0.5 \mu \mathrm{m}$ overlap. To our knowledge, this is the highest frequency operation obtained with any thin film transistor using any material technology. Based on small-signal device models extracted from the measured s-parameters, we expect $\mathrm{f}_{\max }>40 \mathrm{GHz}$ for devices with $\mathrm{L}_{\mathrm{G}}=0.5 \mu \mathrm{m}$.

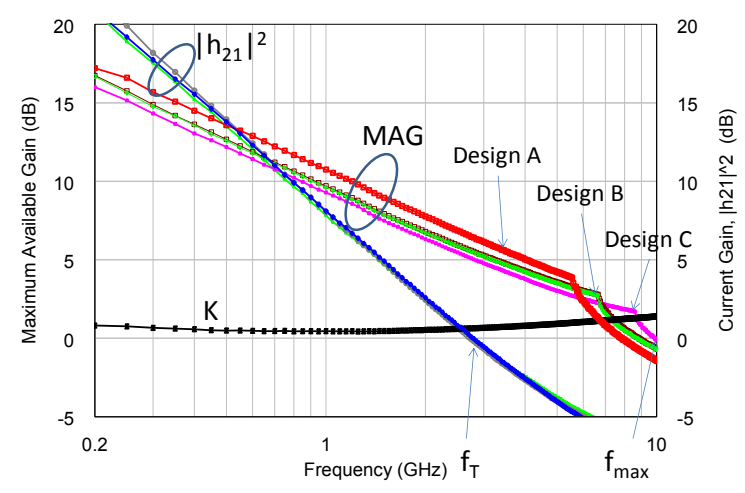

Figure 9: Small signal microwave characteristics of nc- ZnO TFTs TFTs with different gate contact overlap with $\mathrm{S} / \mathrm{D}$ contacts. Devices were bias at $\mathrm{V}_{\mathrm{G}}=6 \mathrm{~V}, \mathrm{~V}_{\mathrm{D}}=11 \mathrm{~V}$.

\section{Transparent Transistors}

$\mathrm{ZnO}$ thin films are suitable for transparent thin film transistor (TTFT) applications because the wide bandgap properties $(3.4 \mathrm{eV})$ of both doped and undoped layers can provide excellent optical transparency. Semiconducting properties of undoped layers make them suitable for the active layers, as shown above, while the doped films can be considered for contact layers. An all-ZnO approach is important for this application because of the high cost and the world-wide shortage of indium caused by the rapidly increasing use of ubiquitous touch screen devices with ITO (indium-tin oxide) transparent conductive oxide (TCO) films [16].

The resistivity, transparency and stability of contact layers made of Al- or Ga-doped $\mathrm{ZnO}$ films were shown to be competitive with indium-based TCOs [17, 18, 19, 20 ]. However, the integration of doped and undoped $\mathrm{ZnO}$ films in the same device faces some technical challenges including low temperature processing for contact layers, auto-doping between layers, and the lack of selective etching between doped and undoped $\mathrm{ZnO}$ films.

We have developed indium-free transparent transistors by replacing the metal contacts of the non-transparent TFTs described above with Ga-doped $\mathrm{ZnO}$ films grown at low temperatures and in an $\mathrm{Ar}$ atmosphere [21]. These Ar-grown TCOs do not require post-growth annealing to achieve low resistivity and therefore comply with the low process temperature budget of $\leq 200^{\circ} \mathrm{C}$. To address the difficulty of selectively etching the contact layer over the channel (both $\mathrm{ZnO}$ ), we employed a thin $\mathrm{Ti}$ etch-stop layer between the source/drain contacts and the transistor channel layer as shown in Figure 10. During processing, the exposed parts of this etch-stop layer oxidized and became a non-conducting $\mathrm{TiO}_{\mathrm{x}}$ surface passivation layer.

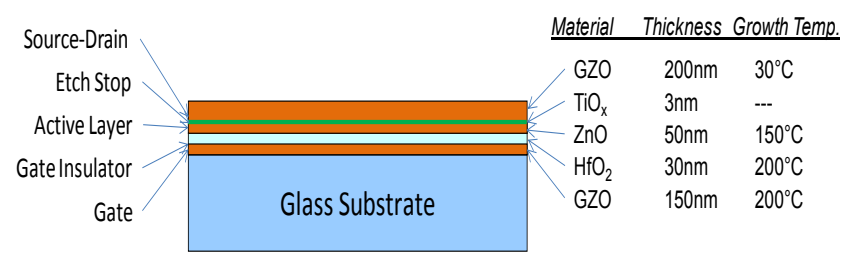

Figure 10: The entire thin film stack of indium-free TTFT grown on a transparent substrate at successively lower growth temperatures.

The entire film stack was grown on glass or quartz substrates before device fabrication and had about $90 \%$ transparency (not including the substrate) in the visible spectrum, as shown in Figure 11. The growth temperature of layers was reduced as the layers were added to minimize the impact of temperature on the properties of the previously grown layers. The gate insulator was $30 \mathrm{~nm}$ thick $\mathrm{HfO}_{2}$ grown by Atomic Layer Deposition (ALD) technique. Mesa etching techniques were used to define S/D contacts, device active area and gate contacts in successive process steps. Figure 12 shows a cross-sectional drawing of the transistor and photograph of several devices with different gate lengths ranging from 5 to $20 \mu \mathrm{m}$. 


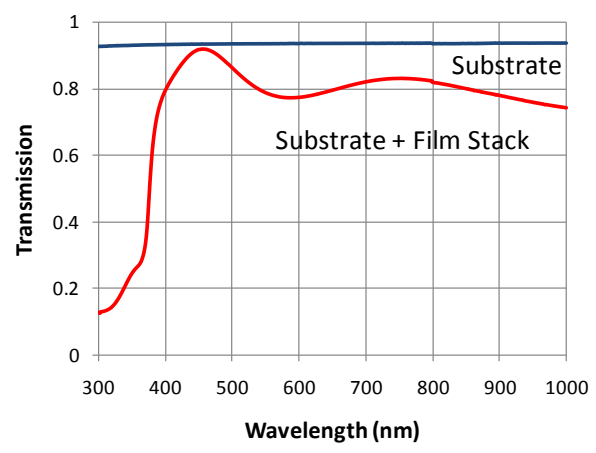

Figure 11: Optical transmission rate for the entire TTFT films and the glass substrate.

(a)

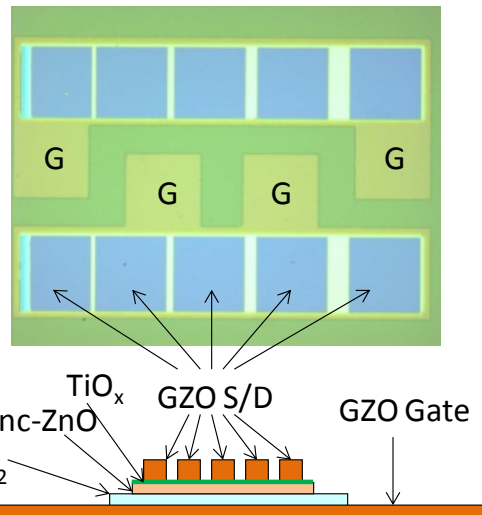

(b)

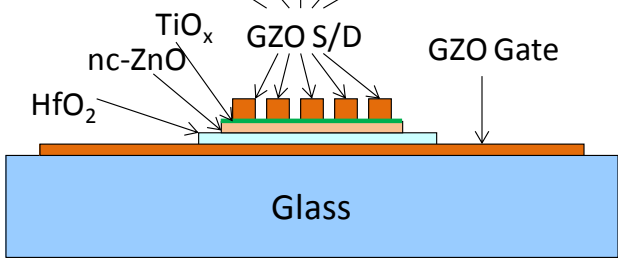

Figure 12: (a) A photograph and, (b) cross sectional drawing of transparent nc-ZnO TFTs. A thin $\mathrm{TiO}_{\mathrm{x}}$ layer is employed as an etch stop layer to facilitate the selective etching of S/D GZO layers.

The linear portion of the I-V characteristics of a device with $\mathrm{L}_{\mathrm{G}}=5 \mu \mathrm{m}$ and $\mathrm{W}_{\mathrm{G}}=70 \mu \mathrm{m}$, shown in Figure 13, indicates that GZO layers make good ohmic contacts to the active layer and there is no evidence of current blocking by the $\mathrm{TiO}_{\mathrm{x}}$ etch stop layer. Also, devices exhibit excellent saturation characteristics for this gate length dimension. The current density was lower than the non-transparent devices fabricated on Si substrates due to thermal limitations of the glass substrate.

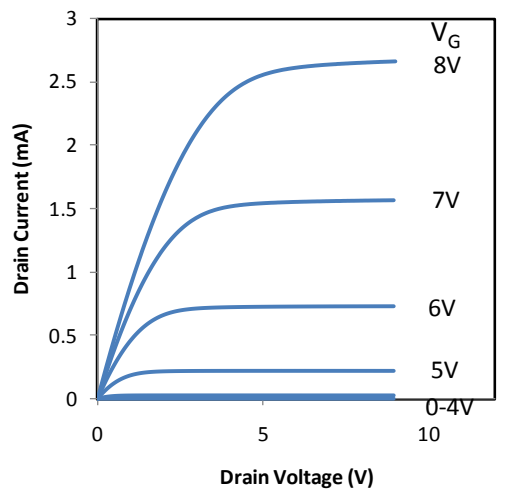

Figure 13: Current-voltage characteristics of nc-ZnO TTFT. $\mathrm{L}_{\mathrm{G}}=5 \mu \mathrm{m}$, $\mathrm{W}_{\mathrm{G}}=70 \mu \mathrm{m}, \mathrm{V}_{\mathrm{G}}=1 \mathrm{~V} /$ step.
The transfer characteristics shown in Figure 14 exhibit an on/off ratio of $5 \times 10^{10}$ and sub-threshold voltage swing of $\mathrm{S}<$ $200 \mathrm{mV} /$ decade. These values are comparable to the values obtained with non-transparent devices fabricated within the same temperature budget.

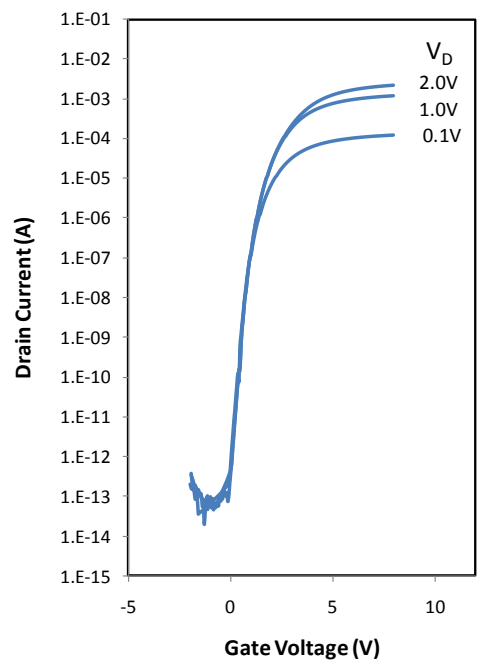

Figure 14: Transfer characteristics of indium-free nc-ZnO TTFT.

The field-effect electron mobility and transconductance values obtained from the transfer characteristics are shown in Figure 15. The threshold voltage, $\mathrm{V}_{\text {th }}=1.6 \mathrm{~V}$, was slightly higher than the value obtained with non-transparent devices (i.e. $\mathrm{V}_{\text {th }}=1.03 \mathrm{~V}$ ). On the other hand, the maximum field effect mobility, $15 \mathrm{~cm}^{2} / V$.s, was lower than the value obtained with non-transparent devices. The measured S value corresponds to an increase in the interface state density to $4.61 \times 10^{12} \mathrm{~cm}^{-2}$ and this can explain the corresponding decrease in mobility. Higher interface state density can be caused by the $\mathrm{ZnO}-\mathrm{HfO}_{2}$ interface roughness [22] due to rougher gate contact layer surfaces compared to metal gates used in non-transparent devices. Improvements in the surface morphology of the doped nc- $\mathrm{ZnO}$ gate contact layer are expected to bring closer the performance metrics of the transparent and non-transparent transistors. Nevertheless, to our knowledge, the performance values reported here represent the highest values obtained with indium-free transparent thin film transistors.

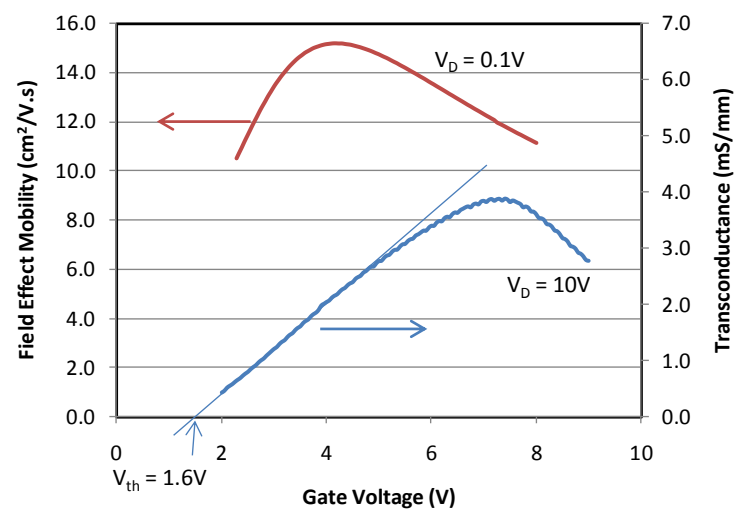

Figure 15: Field effect mobility and transconductance of indium-free nc$\mathrm{ZnO}$ TTFT as a function of gate voltage. 


\section{SUMMARY AND CONCLUSIONS}

PLD-grown $\mathrm{ZnO}$ thin films were used to fabricate high speed and transparent thin film transistors. TEM and X-ray examination showed that films consisted of closely packed nanocolumns of $\mathrm{ZnO}$ with predominantly (002) orientation and $20-50 \mathrm{~nm}$ diameter. Films maintained their ordered structure conformably over non-planar surfaces. We have studied doped and undoped films grown on various gate insulators and at low substrate temperatures for high speed and transparent thin film transistor applications. Excellent switching characteristics (on/off ratios greater than $10^{12}$ ), sub-threshold voltage swing $(\mathrm{S}=85 \mathrm{mV} /$ decade $)$ and field effect mobilities $\left(63 \mathrm{~cm}^{2} / \mathrm{V} . \mathrm{s}\right)$ were obtained with low temperature grown films. We attributed these superior performances of nc-ZnO TFTs to the high crystal quality preserved within nanocrystals and the presence of acceptorlike states at the vertical grain boundaries due to $\mathrm{Zn}$ vacancies. High speed performance was demonstrated by devices fabricated on Si substrates with the achievement of current gain cut-off frequency of $2.9 \mathrm{GHz}$ and power gain cut-off frequency of $10 \mathrm{GHz}$. Doped and undoped nc- $\mathrm{ZnO}$ films were integrated on glass substrates using etch stop layers to fabricate the first all-ZnO TTFTs with record performance. Indium-free TTFTs are important to address the cost and availability issues related to indium.

\section{ACKNOWLEDGMENT}

This work was supported in part by AFOSR under LRIR No: 07SN03COR (Program Manager: Dr. Kitt Reinhart). The authors thank D. Agresta, J. Brown, R. and D. Tomich for optical transmission, AFM and XRD analyses, respectively. Valuable discussions with Drs. R.C. Scott and D. Look are also acknowledged.

\section{REFERENCES}

[1] C. R. Kagan and P. Andry, "Thin film transistors", Marcel Dekker Publishing, New York, 2003.

[2] K. Nomura et al, "Room temperature fabrication of transparent flexible thin-film transistors using amorphous oxide semiconductors," Nature, vol. 432, pp. 488-492, 2004.

[3] B. Bayraktaroglu, K. Leedy, and R. Neidhard, "Nanocrystalline $\mathrm{ZnO}$ Microwave Thin Film Transistors", Proc. of SPIE, vol. 7679, pp.767904-1, 2010.

[4] R. C. Scott, K. Leedy, B. Bayraktaroglu, D. C. Look, and Y-H. Zhang, "Effects of $\mathrm{Ar}$ vs. $\mathrm{O}_{2}$ ambient on pulsed-laser-deposited Ga-doped ZnO”, J. of Cryst. Growth, vol. 324, pp. 110-114, 2011.

[5] L. Bentes, R. Ayouchi, C. Santos, R. Schwarz, P. Sanguino, O. Conde, M. Peres, T. Monteiro, and O. Teodoro, "ZnO films grown by laser ablation with and without oxygen CVD," Superlattices and Microstructures, vol. 42, pp. 152-157, 2007.

[6] S. Amirhaghi, V. Craciun, D. Craciun, J. Elders and I. W. Boyd, "Low temperature growth of highly transparent c-axis oriented $\mathrm{ZnO}$ thin films by pulsed laser deposition," Microelectronics Engineering, vol. 25, pp. 321-326, 1994.

[7] L. Han, F. Mei, C. Liu, C. Pedro, and E. Alves, "Comparison of ZnO thin films grown by pulsed laser deposition on sapphire and $\mathrm{Si}$ substrates," Physica E, vol. 40, pp. 699-704, (2008).

[8] C-F. Yu, C-W. Sung, S-H. Chen, and S-J. Sun, "Relationship between the photoluminescence and conductivity of undoped $\mathrm{ZnO}$ thin films grown with various oxygen pressures," Appl. Surface Sci., vol. 256, pp. 792-796, 2009.

[9] B. Bayraktaroglu, K. Leedy, and R. Neidhard, " $\mathrm{ZnO}$ thin film transistors for RF applications," Mater. Res. Soc. Symp. Proc., Vol. 1201, pp. H09-07, (2010).

[10] A. Roland, J. Richard, J.P. Kleider and D. Mencaraglia, "Electrical properties of amorphous silicon transistors and MIS-devices: Comparative study of top nitride and bottom nitride configurations,' J. Electrochem. Soc., vol. 140, pp. 3679-3683, 1993.

[11] B. Bayraktaroglu, K. Leedy, and R. Neidhard, "Microwave $\mathrm{ZnO}$ thinfilm transistors," IEEE Electron Dev.Lett., vol. 29, pp. 1024-1026, 2008.

[12] R. C. Scott, K. Leedy, B. Bayraktaroglu, D. Look, and Y-H. Zhang, "Effects of Ar vs.O2 ambient on pulsed-laser-deposited Ga-doped ZnO," J. Crystal Growth, vol. 324 pp. 110-114, 2011.

[13] D. R. Clarke, "Varistor Ceramics," J. Am. Ceram. Soc., vol. 82, pp.485-502, 1999.

[14] J. Albrecht, P. P. Ruden, S. Limpijumnong, W. R. Lambrecht and K F. Brennan, "High field electron transport properties of bulk $\mathrm{ZnO}$," J. of Appl. Phys., vol. 86, pp. 6864-6867, Dec. 1999.

[15] B. Bayraktaroglu, K. Leedy and R. Neidhard, "High-frequency ZnO thin film transistors on Si substrates," IEEE Electron Dev. Lett., vol.30, pp.946-948, 2009.

[16] B. O'Neill, "Indium market forces, a commercial perspective," 35th IEEE Photovoltaic Specialists Conference (PVSC) Proceedings, DOI: 10.1109/PVSC.2010.5616842, 2010.

[17] H. Agura, A. Suzuki, T. Matsushita, T. Aoki, and M. Okuda, "Low resistivity transparent conducting Al-doped $\mathrm{ZnO}$ films prepared by pulsed laser deposition," Thin Solid Films, vol. 445, pp.263-267, 2003

[18] B. Bayraktaroglu, K. Leedy and R. Bedford, "High temperature stability of postgrowth annealed transparent and conductive $\mathrm{ZnO}: \mathrm{Al}$ films," Appl. Phys. Lett., vol. 93, 022104, 2008.

[19] T. Minami, S. Ida, and T. Miyata, "High rate deposition of transparent conducting oxide thin films by vacuum arc plasma evaporation," Thin Solid Films, vol. 416, pp. 92-96, 2002.

[20] R. C. Scott, K. Leedy, B. Bayraktaroglu, D. Look, D. Smith, D. Ding, $\mathrm{X}$. Lu, and Y-H. Zhang, "Influence of Substrate Temperature and Post-Deposition Annealing on Material Properties of Ga-Doped $\mathrm{ZnO}$ Prepared by Pulsed Laser Deposition," J. Electronic Mat, vol. 40, pp.419-428, 2010.

[21] R. C. Scott, K. Leedy, B. Bayraktaroglu, D. Look, and Y-H. Zhang, "Highly conductive $\mathrm{ZnO}$ grown by pulsed laser deposition in pure Ar”, Appl. Phys. Lett., vol. 97, 072113, 2010.

[22] K.Okamura and H. Hahn, "Carrier transport in nanocrystalline fieldeffect transistors: Impact of interface roughness and geometrical carrier trap," Appl. Phys. Lett., vol. 97, 153114, 2010. 